\title{
Valuable contribution to the study of multilingualism in South Africa
}

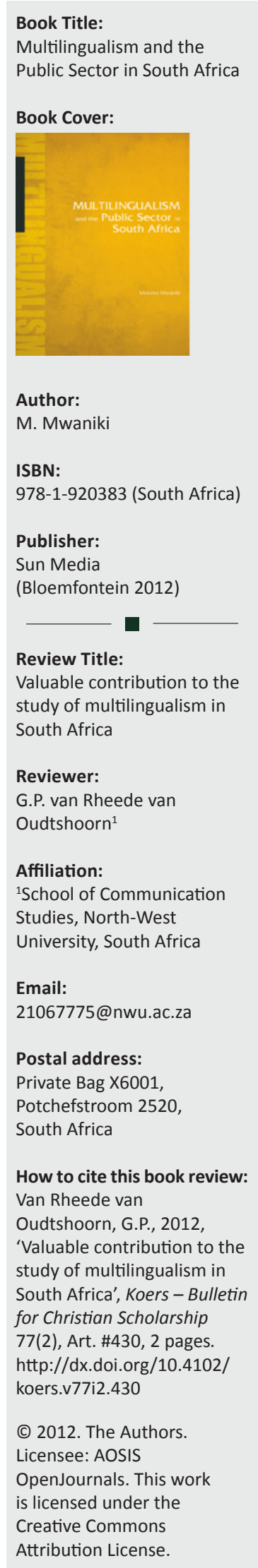

Doctor Munene Mwaniki offers a valuable contribution to the discourse on language in South Africa. In this thoroughly unpacked analysis of multilingualism in the South African context, Mwaniki provides a rich resource which is much needed when engaging in the debate on language and the management thereof in the public sector. The themes and contexts selected for inclusion in the book are selected with care and motivated judgement. The book focuses predominantly on the place of multilingualism in the South African public sector. It argues for the re-engineering of the dominant bilingual state (English or Afrikaans) of the public sector towards multilingualism. The book addresses the vision of multilingualism from a constitutional view and makes a pragmatic contribution towards implementation of multilingualism in legislative, human resource and service delivery spheres.

The logic followed in addressing the topic of the book is deductive. Often, the argument for multilingualism starts by an exploration and discussion of the context - historical, constitutional, the public sector per se and organisational culture. It incorporates the several influences in language management within the parameters of the public sector and considers process and context in its wake. The reader is never left with the feeling that the statement or argument is summarily made and built upon. From the very first page, and every page thereafter, the reader is provided with some degree of proof that this book is the product of wide consultation and the consideration of an array of sources.

Mwaniki offers insight into how the South African constitution is paradigmatically geared towards multilingualism. He does more than just explain the basic ideas behind language and the constitution; he provides an analysis of the language of the constitution and gifts the reader with multidimensional interpretations thereof. He plots the way forward and explains, through careful argumentation, why and how multilingualism should and can be harnessed as a resource. The argument is so strong that the reader is left with eagerness to participate in and promote multilingualism in South Africa.

The contents of the book is extensively referenced, rooted in a more than sufficient analysis of theory, and packed with an impressive measure of context. It is most assuredly a well-structured analysis of the current South African situation regarding multilingualism from a theoretical and legislative point of departure and offers valuable contributions towards the case for multilingualism in the public sector. It is impressive that the arguments are well backed with scholarly debate on the matter and not grabbed from an emotional pool of unsubstantiated throw-away arguments.

The most idealistic parts of the book are the sections dealing with the human resource challenges of implementing multilingualism. Although a strong case is made for public sector human resource management, in step with the rest of the book, the problematic South African context is not as strongly considered. The author makes invaluable proposals, but given the current lack of service delivery in the public sector, the reader is left sceptical regarding the workability and feasibility of the author's proposals. There is no doubt that, in theory, the proposals made are impressive and impressively presented. But there is still a long way to go in terms of making it work in the public sector.

However, the daunting task is one that merits effort. It is in this argument that the author exceeds expectations and impresses the reader.

The book will be of great use for scholars and students in the field of language studies. The book is nestled primarily in theories that are studied in language studies. In addition to the field of language, the book addresses multilingualism in a broader sense: the contexts of public administration, constitutional law, human resources and intercultural communication are all well served. It must be noted though that scholars in language studies (and language management) and public administration will benefit most from this book. 
It seems that this book provides such valuable contributions to language management in the public sector that South Africans in general will find the arguments made in the book beneficial to how we think about multilingualism. The book is not written for the general public; its style is not conducive to considerations of light reading. Still, the contribution is of worth to all manner of readers.

Mwaniki follows an academic writing style, which obviously benefits students and scholars alike as the book is coded in a style that resonates with the epistemology of language. The author uses a strong theoretical base as a point of departure, and roots arguments in known theory and sound theoretical argumentation. The fact that the historical influences and several theoretical approaches from which to engage in the language debate are considered, offers a hermeneutical depth that reflects the multi-angled reasoning typical in scholarly analysis. The author succeeds in wrapping himself in voices in the multilingualism debate, and emerges with the thesis that the public sector ought to function multilingually. 